\title{
Studi Penanganan Ruas Jalan Bulu - Batas Kota Tuban Provinsi Jawa Timur Menggunakan Data FWD dan Data Mata Garuda
}

\author{
Rahmi Zurni, Welly Pradipta, Ganny Rian Kusnandar \\ Jurusan Teknik Sipil, Institut Teknologi Nasional, Bandung \\ e-mail: me.rahmi.amie@gmail.com
}

\begin{abstract}
ABSTRAK
Kondisi jalan di Indonesia saat ini cukup mengkhawatirkan, banyak jalan di Indonesia yang mengalami kerusakan, oleh karena kondisi jalan tersebut memerlukan penanganan yang serius. Penanganan yang sesuai akan menjaga jalan tetap pada kondisi pelayanan mantap. Penanganan jalan dianalisis menggunakan metode AASHTO 1993, dimana hasilnya berupa nilai SN (Structural Number). Nilai SN sangat dipengaruhi oleh data lendutan dari alat FWD dan data International Roughness Index dari survei alat Mata Garuda.Perbandingan nilai $S N_{\text {eff }}$ dengan $S N_{f}$ menghasilkan nilai SCI (Stuctural Condition Index) yang menentukan penanganan jalan tersebut. Dari hasil analisis diperoleh nilai SCI yang bervariasi, sehingga menghasilkan penanganan jalan yang berbeda-beda setiap segmennya. Nilai SCI terendah adalah 0,18 dengan penanganan berupa rekontruksi, sedangkan untuk nilai SCI terbesar adalah 1,19 dengan penanganan berupa pemeliharaan.
\end{abstract}

Kata kunci: penanganan jalan, lendutan, mata garuda

\begin{abstract}
The road condition in Indonesia is quite alarming, many roads in Indonesia that was damaged, therefore that condition of the road require serious treatment. Proper treatment will keep the road stay in good service condition. Road treatment analyzed by using AASHTO 1993 method, where the result is the value of $S N$ (Structural Number). The value of SN is very affected by deflection data from FWD tools and International Roughness Index data that surveyed from Mata Garuda tools. The comparison of $S N_{\text {eff }}$ value and $S N_{f}$ value resulting SCI (Structural Condition Index) value that determine the treatment of that road. The analysis resulting variated SCI value, so the road treated differently on each segment. The lowest SCI value is 0.18 with the reconstruction road treatment, meanwhile the highest SCI value is 1.19 with the maintenance road treatment.
\end{abstract}

Keywords: road maintenance, deflection, mata garuda 


\section{PENDAHULUAN}

Penentuan penanganan jalan sangat dipengaruhi oleh repetisi beban kendaraan. Besarnya nilai repetisi beban kendaraan yang melintas sangat mempengaruhi kondisi jalan sehingga dapat menimbulkan adanya kerusakan pada jalan. Penanganan jalan yang tepat akan mengurangi dan mencegah kerusakan yang terjadi pada jalan, sehingga membuat jalan tetap pada kondisi mantap. Salah satu cara untuk menentukan penanganan jalan dapat menggunakan data Falling Weight Deflectometer (FWD) dan data survei Mata Garuda.

Terdapat beberapa rumusan masalah dalam penelitian ini, yaitu (1) Menentukan penanganan jalan untuk ruas jalan Bulu - Batas Kota Tuban Provinsi Jawa Timur, (2) Studi kasus pada ruas jalan Bulu Batas Kota Tuban Provinsi Jawa Timur.

Tujuan dari penelitian ini adalah menentukan prioritas penanganan ruas jalan Bulu - Batas Kota Tuban Provinsi Jawa Timur dengan menggunakan data Falling Weight Deflectometer dan survei Mata Garuda. Sedangkan manfaat dari penelitian ini diantaranya memberikan alternatif penanganan jalan untuk ruas jalan Bulu - Batas Kota Tuban Provinsi Jawa Timur, yang nantinya dapat dijadikan salah satu alternatif penanganan jalan berdasarkan nilai $S C I$.

Ruang lingkup Penelitian ini, adalah:

1. Penelitian dilakukan menggunakan data FWD dan data survei Mata Garuda dengan menggunakan metode ASSHTO 1993.

2. Penelitian hanya fokus menentukan penanganan untuk ruas jalan Bulu - Batas Kota Tuban Provinsi Jawa Timur.

3. Segmentasi penanganan dilakukan diakhir setelah penentuan penanganan.

4. Hasil akhir penelitian tidak mempertimbangkan terhadap jumlah biaya.

5. Penelitian ini dilakukan untuk simulasi bukan untuk evaluasi.

\section{TINJAUAN PUSTAKA}

\subsection{Penentuan IRI}

Nilai IRI yang menjadi parameter kekasaran jalan yang dihitung dari jumlah kumulatif naik turunnya arah profil memanjang dibagi dengan jarak atau panjang permukaan yang diukur didapat dari hasil survei Mata Garuda. Kondisi jalan berdasarkan nilai IRI ditunjukan seperti pada Tabel 1. [2]

Tabel 1. Penilaian Kondisi Jalan Berdasarkan Nilai IRI [2]

\begin{tabular}{ccc}
\hline Nilai IRI & Kondisi Jalan & Jenis Penanganan \\
\hline$<4$ & Baik & Pemeliharaan Rutin \\
\hline $4-8$ & Sedang & Pemeliharaan Rutin \\
\hline $8-12$ & Rusak Ringan & Pemeliharaan Berkala \\
\hline$>12$ & Rusak Berat & Peningkatan/Rekonstruksi \\
\hline
\end{tabular}

\subsection{Perhitungan $S N_{\text {eff }}$}

Perhitungan $S N_{\text {eff }}$ menggunakan data lendutan hasil survei FWD. Data yang diperlukan untuk perhitungan $S N_{\text {eff }}$ ini adalah sebagai berikut: (1) data lendutan balik hasil survei FWD; (2) nilai modulus resilient tanah dasar; (3) tebal lapisan perkerasan; (4) modulus efektif perkerasan; (5) $a_{e}$ atau jari-jari gelembung tegangan pada bidang pertemuan tanah-dasar dan perkerasan.

Modulus Resilient tanah dasar didapat dari Persamaan 1. 


$$
M_{R}=C \frac{0,24 P}{d_{r} r}
$$

dimana:

$M_{R}=$ Modulus Resilient tanah dasar dari hitungan balik (psi),

$P \quad=$ beban dalam uji FWD (lb),

$d_{r}=$ defleksi FWD pada jarak $\mathrm{r}$ dari pusat beban (inch),

$r \quad=$ jarak dari pusat beban FWD (inch),

$C \quad=$ faktor koreksi $=1$.

Modulus perkerasan efektif sebagai indikator kekakuan sistem perkerasan diatas tanah dasar ditentukan dari defleksi di pusat beban seperti pada Persamaan 2.

$$
d_{o}=1,5 p a\left\{\frac{1}{M_{R} \sqrt{1+\left(\frac{D^{3}}{a} * \sqrt{\frac{E_{p}}{M_{\mathrm{R}}}}\right)^{2}}}+\left[\frac{1-\frac{1}{\sqrt{1+\left(\frac{D}{a}\right)^{2}}}}{E_{p}}\right]\right\}
$$

dimana:

$d_{o}=$ defleksi hasil pengukuran di pusat beban (inch),

$p=$ tekanan akibat beban pada pelat FWD (psi),

$a \quad=$ jari-jari pelat beban (inch),

$D=$ tebal total lapisan perkerasan di atas tanah-dasar (inch),

$E_{p}=$ modulus efektif seluruh lapisan perkerasan di atas tanah dasar (psi).

Nilai $d_{o}$ perlu disesuaikan dengan temperatur standar $68^{\circ} \mathrm{F}$. AASHTO 1993 memberikan cara penyesuaian $d_{o}$ untuk campuran beton aspal dengan lapis fondasi dan distabilisasi aspal seperti pada Gambar 2.

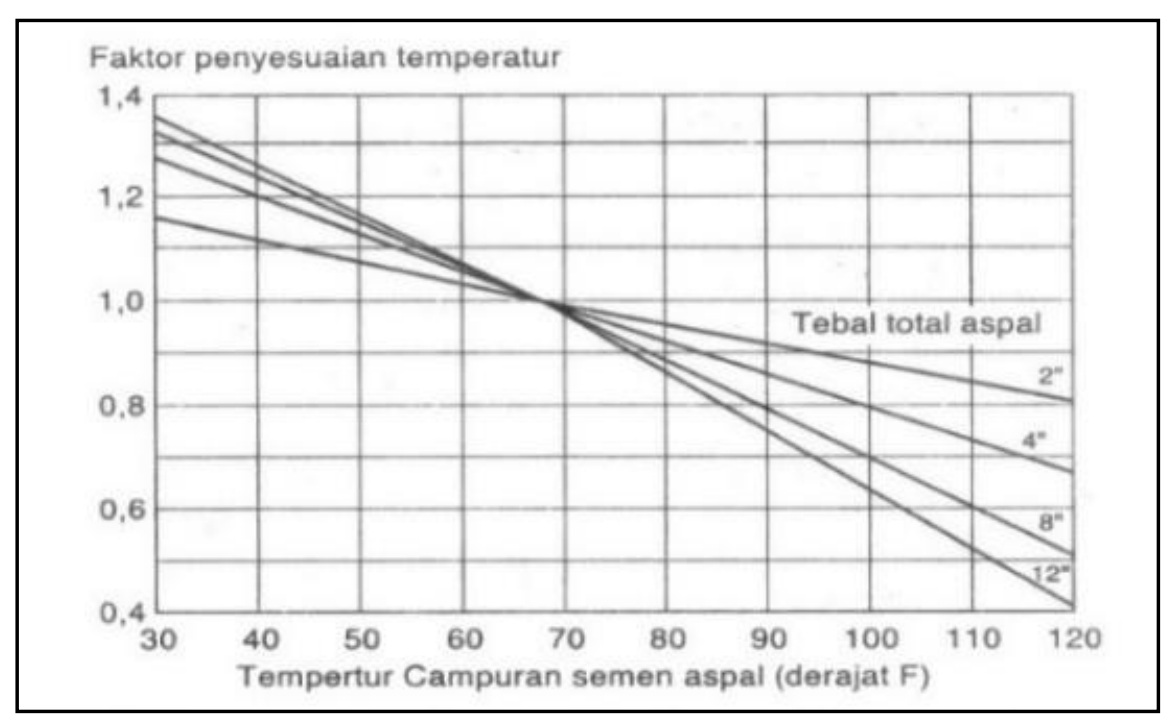

Gambar 2. Faktor Penyesuaian untuk $d_{o}[1]$ 
Jarak minimum pengukuran $M_{R}$ ditentukan pada Persamaan 3 dan syarat jarak minimum dalam pengukuran $M_{R}$ tanah dasar ditentukan dengan Persamaan 4.

$$
\begin{gathered}
a_{e}=\sqrt{a^{2}+\left(D \sqrt[3]{\frac{E_{p}}{M_{R}}}\right)^{2}} \\
r \geq(0,7)\left(a_{e}\right)
\end{gathered}
$$

dimana:

$a_{e}=$ jari-jari gelembung tegangan pada bidang pertemuan tanah-dasar dan perkerasan,

$r=$ jarak dari pusat beban (in).

Nilai $S N_{\text {eff }}$ diperoleh dari analisis data FWD seperti pada Persamaan 5.

$$
S N_{\text {eff }}=0,0045 D^{3} \sqrt{E_{p}}
$$

\subsection{Penentuan Umur Sisa}

Umur sisa perkerasan dapat menunjukan kondisi perkerasan ketika telah mengalami kelelahan dengan memperhatikan kerusakan akibat kelelahan. Kenaikan volume lalu lintas membuat perkerasan mengalami kelelahan, sehingga perkerasan mengalami penurun kualitas strukturalnya. Umur sisa perkerasan dapat dihitung menggunakan Persamaan 6.

$$
R_{L}=100\left[1-\left(\frac{N_{p}}{N_{1,5}}\right)\right]
$$

dimana:

$R_{L} \quad=$ sisa umur perkerasan dalam persen,

$N_{p} \quad=$ lalu lintas total sekarang,

$N_{l, 5}=$ lalu lintas total ketika perkerasan hancur.

\subsection{Penentuan Structural Number}

Structural Number $(S N)$ didefinisikan sebagai angka indeks yang berasal dari analisis lalu lintas, kondisi tanah dasar, dan faktor regional. Angka struktural $S N$ dapat dihitung dengan Persamaan 7.

$$
S N=\left(a_{1} * D_{1}\right)+\left(a_{2} * D_{2} * m_{2}\right)+\left(a_{3} * D_{3} * m_{3}\right)
$$

dimana:

$D_{1} \quad=$ tebal lapis permukaan (inch),

$D_{2} \quad=$ tebal lapis fondasi (inch),

$D_{3} \quad=$ tebal lapis fondasi bawah (inch),

$m_{2} \quad$ = koefisien drainase lapis fondasi,

$m_{3} \quad=$ koefisien drainase lapis fondasi bawah,

$a_{1}=$ koefisien lapisan untuk lapis permukaan,

$a_{2} \quad=$ koefisien lapis fondasi, 
$a_{3} \quad=$ koefisien lapis fondasi bawah.

\subsection{Penentuan $S N_{f}$}

SNf ditentukan melalui persamaan yang dibuat oleh AASHTO. Parameter-parameter yang dibutuhkan dalam persamaan tersebut yaitu $\triangle P S I$, Reliabilitas, $M_{R}$, Standar Deviasi, $Z_{R}$, dan ESAL. ESAL (Equivalent Single Axel Load) dipengaruhi oleh beberapa faktor yaitu volume kendaraan, ekivalensi sumbu standar kendaraan, distribusi arah, distribusi lajur, dan umur rencana. Perhitungan ESAL dihitung dengan menggunakan Persamaan 8, nilai $S N_{f}$ digunakan Persamaan 9.

$$
E S A L=\Sigma L H R * E * D_{A} * D_{L} * 365 * N
$$

dimana:

$E S A L=$ repetisi beban lalu lintas selama umur rencana, $l s s / L R / U R$,

$L H R=$ lalu lintas harian rata-rata,

$E \quad=$ angka ekivalen sumbu standar,

$D_{A} \quad=$ faktor distribusi arah; $D_{A}=1$,

$D_{L} \quad=$ faktor distribusi lajur; $D_{L}=1$,

$365=$ jumlah hari dalam satu tahun,

$N \quad=$ faktor umur rencana.

$$
\log \left(N_{f}\right)=Z_{R} * S_{0}+9,36 * \log \left(S N_{f}+1\right)-0,2+\frac{\log \left[\frac{\Delta P S I}{4,2-1,5}\right]}{0,4+\frac{1094}{\left(S N_{f}+1\right)^{5,19}}}+2,32 * \log \left(M_{R}\right)-8,07
$$

dimana:

$S N_{f}=$ structural number rencana,

$N_{f} \quad=$ repetisi beban lalu lintas di masa datang $(E S A L)$,

$Z_{R} \quad$ = simpangan baku normal,

$S_{0} \quad=$ deviasi standar keseluruhan (bernilai 0,4-0,5),

$\triangle P S I=$ perbedaan serviceability index di awal dan di akhir umur rencana,

$M_{R} \quad=$ Modulus Resilient tanah dasar.

\subsection{Penentuan SCI}

Nilai Structural Condition Index (SCI) dijadikan sebagai parameter penentuan penanganan jalan yang dilihat dari nilai $S N_{\text {eff }}$ dan nilai $S N_{f}$ seperti pada Persamaan 10.

$$
\frac{S N_{\text {eff }} \min }{S N_{f}} \leq 0,7
$$

Jika nilai $\frac{S N_{e f f}}{S N_{f}}$ lebih kecil dari 0,07 maka jalan memerlukan overlay, namun jika nilai $\frac{S N_{e f f}}{S N_{f}}$ lebih besar maka jalan tidak memerlukan overlay. 


\subsection{Penanganan Berdasarkan Indikator Fungsional Dan Struktural}

Nilai $S C I$ digunakan sebagai penentu penanganan perkerasan, yang dapat dikategorikan seperti pada Tabel 2.[2]

Tabel 2. Penanganan Jalan berdasarkan Nilai SCI [2]

\begin{tabular}{cc}
\hline $\boldsymbol{S C I}$ & Penanganan \\
\hline$>1$ & Pemeliharaan \\
\hline $0,7-1$ & Overlay Fungsional \\
\hline $0,5-0,7$ & Overlay Struktural \\
\hline$<0,5$ & Rekontruksi \\
\hline
\end{tabular}

\section{PRESENTASI DATA}

Data yang dikumpulkan merupakan data sekunder yang didapat dari BPJN wilayah V Jawa Timur. Data-data yang dikumpulkan, yaitu:

1. Data kondisi lalu lintas,

Data lalu lintas berupa volume lalu lintas selama tahun 2015. Data lalu lintas yang didapat dikelompokkan menurut golongan kendaraan berdasarkan komposisi kendaraan yang diperoleh dari survei lalu lintas.

2. Data kondisi perkerasan,

Data yang didapat yaitu data struktur perkerasan dan data lendutan. Kedua data ini adalah gambaran lengkap kondisi perkerasan lentur pada ruas jalan yang ditinjau, yaitu data struktur perkerasan existing dan data lendutan hasil pengukuran dengan alat FWD.

3. Data lendutan hasil pengukuran dengan alat FWD dan data temperatur perkerasan,

Data temperatur didapatkan bersama dengan data lendutan. Pada saat pengukuran lendutan dicatat pula data temperatur udara dan temperatur perkerasan.

4. Survei dilakukan dengan menggunakan kendaraan survei jalan yang dapat mengumpulkan data kondisi permukaan jalan secara cepat. Data yang didapat dari survei mata garuda berupa data IRI seperti pada Gambar 3.

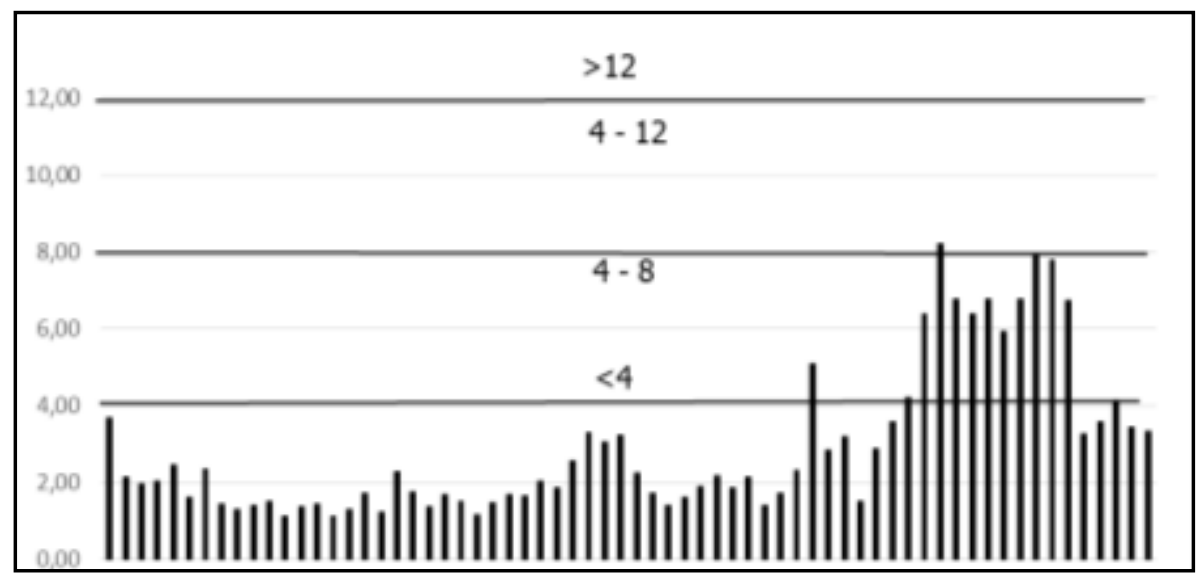

Gambar 3. Nilai IRI STA 107+400 - STA 113+900 


\section{ANALISIS DAN PEMBAHASAN}

\subsection{Analisis Lalu Lintas}

Tingkat pertumbuhan lalu lintas diasumsikan sebesar 5\% untuk selama 5 tahun. Faktor ekivalensi beban sumbu standar menggunakan nilai Vehicle Damage Factor (VDF) pangkat 5. Nilai VDF yang digunakan pada perhitungan nilai ESAL dapat dilihat pada Tabel 3. [3]

Tabel 3 Nilai VDF [3]

\begin{tabular}{ccc}
\hline $\begin{array}{c}\text { Jenis } \\
\text { Kendaraan } \\
\text { Klasifikasi Lama }\end{array}$ & Uraian Kendaraan & $\begin{array}{c}\text { Faktor Ekivalensi } \\
\text { Beban Pangkat }\end{array}$ \\
\hline $5 \mathrm{a}$ & Bus kecil & 0,2 \\
\hline $5 \mathrm{a}$ & Bus besar & 1 \\
\hline $6 \mathrm{a} .1$ & Truk 2 sumbu-ringan & 0,2 \\
\hline $6 \mathrm{a} .2$ & Truk 2 sumbu - ringan kargo & 0,8 \\
\hline $6 \mathrm{~b} 1.1$ & Truk 2 sumbu-medium & 0,7 \\
\hline $6 \mathrm{~b} 1.2$ & Truk 2 sumbu-medium kargo & 1,7 \\
\hline $6 \mathrm{~b} 2.1$ & Truk 2 sumbu-berat & 0,8 \\
\hline $6 \mathrm{~b} 2.2$ & Truk 2 sumbu-berat kargo & 11,2 \\
\hline $7 \mathrm{a} 1$ & Truk 3 sumbu & 11,2 \\
\hline $7 \mathrm{a} 2$ & Truk 3 sumbu kargo & 64,4 \\
\hline $7 \mathrm{a} 3$ & Truk 3 sumbu sumbu kendali ganda & 62,2 \\
\hline $7 \mathrm{~b}$ & Truk 2 sumbu dan trailer penarik 2 sumbu & 90,4 \\
\hline $7 \mathrm{c} 1$ & Truk 4 sumbu-trailer & 24 \\
\hline $7 \mathrm{c} 2.1$ & Truk 5 sumbu-trailer & 33,2 \\
\hline $7 \mathrm{c} 2.2$ & Truk 5 sumbu-trailer & 69,2 \\
\hline $7 \mathrm{c} 3$ & Truk 6 sumbu-trailer & 93,7 \\
\hline
\end{tabular}

\subsection{Analisis Kumulatif ESAL}

Nilai Kumulatif ESAL adalah jumlah kumulatif repetisi beban sumbu standar $18000 \mathrm{lbs}$ selama satu tahun, yang diperoleh dengan mengalikan volume lalu lintas harian rata-rata pada tahun yang ditinjau dengan faktor ekivalensi beban sumbu standar, faktor pertumbuhan lalu lintas dan koefisien distribusi lajur rencana. Perhitungan kumulatif ESAL didasarkan pada volume lalu lintas harian $(L H R)$ yang dikonversikan menjadi nilai ESAL. Faktor distribusi arah dan lajur rencana ruas jalan Bulu - Batas Kota Tuban Provinsi Jawa Timur adalah 1. Resume dari analisa perhitungan ESAL dapat dilihat pada Tabel 4.

Tabel 4. Nilai Kumulatif ESAL

\begin{tabular}{cccccccr}
\hline Gol.Kend & $\boldsymbol{L H R}$ & $\boldsymbol{V D F}$ & $\boldsymbol{D}_{\boldsymbol{L}}$ & $\boldsymbol{D}_{\boldsymbol{A}}$ & $\begin{array}{c}\text { Jumlah Hari 1 } \\
\text { Tahun }\end{array}$ & $\boldsymbol{N}$ & \multicolumn{1}{c}{$\boldsymbol{E S \boldsymbol { A } L}$} \\
\hline 5a & 95 & 0,2 & 1 & 1 & 365 & 5,53 & 38.149 \\
\hline 5b & 275 & 1 & 1 & 1 & 365 & 5,53 & 555.276 \\
\hline 6a & 74 & 0,2 & 1 & 1 & 365 & 5,53 & 29.671 \\
\hline 6b & 2815 & 0,8 & 1 & 1 & 365 & 5,53 & 4.545 .630 \\
\hline 7a & 2223 & 62,20 & 1 & 1 & 365 & 5,53 & 279.073 .460 \\
\hline 7b & 247 & 90,4 & 1 & 1 & 365 & 5,53 & 45.023 .949 \\
\hline 7c & 627 & 24 & 1 & 1 & 365 & 5,53 & 30.366 .369 \\
\hline & & & & & & Total $E S A L=$ & 359.632 .505 \\
\hline
\end{tabular}




\subsection{Analisis Dan Pembahasan Kondisi Struktural}

Hasil analisis IRI diperoleh persentase kondisi jalan pada ruas yang ditinjau adalah sebesar $86 \%$ kondisi baik dengan nilai IRI $<4$, 13\% dalam kondisi sedang dengan nilai IRI $4-8$, dan $1 \%$ dalam kondisi rusak dengan nilai IRI 8 -12. Gambar 4 memperlihatkan persentase kondisi jalan dilihat dari nilai IRI.

Pengolahan data LHR dilakukan untuk memperoleh besarnya volume lalu lintas yang menggunakan ruas jalan yang dikaji pada tahun pengamatan, dengan mengasumsikan nilai pertumbuhan lalu lintas sebesar 5\% pertahun. Perhitungan ESAL dilakukan dengan menggunakan nilai VDF dari Manual Desain Perkerasan Bina Marga tahun 2013 [3]. Penggunaan VDF digunakan untuk kendaraan berat dengan Golongan 5a - 7c, sehingga diperoleh total nilai $E S A L=359.632 .505$ lss $/ L R / U R$.

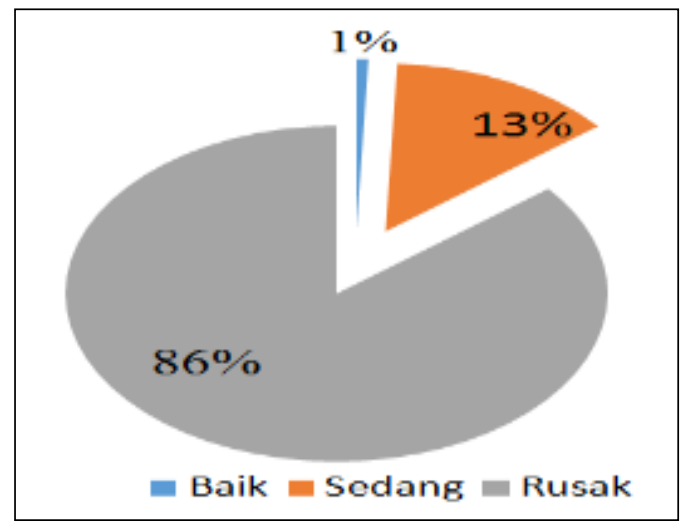

Gambar 4. Grafik Persentase Kondisi Jalan Berdasarkan Nilai IRI

Analisis nilai $S C I$ sangat dipengaruhi oleh data lendutan yang diperoleh dari survei FWD dan data IRI yang diperoleh dari survei Mata Garuda. Data lendutan dan IRI tersebut akan diolah untuk mencari besaran $S N_{\text {eff }}$ dan $S N_{f}$ dari perkerasan jalan. Berdasarkan nilai $S N_{\text {eff }}$ dan $S N_{f}$ didapatkan nilai $S C I$ yang digunakan untuk penentuan penanganan jalan. Hasil perhitungan $S C I$ diperoleh bahwa penanganan jalan sebelum dipisahkan secara segmentasi untuk kedua arah diurut dari persentase penanganan terbesar yaitu melakukan rekonstruksi, overlay struktural, overlay fungsional dan persentase paling kecil yaitu kegiatan pemeliharaan jalan. Persentase program penanganan jalan dapat dilihat pada Gambar 5 dan Gambar 6.

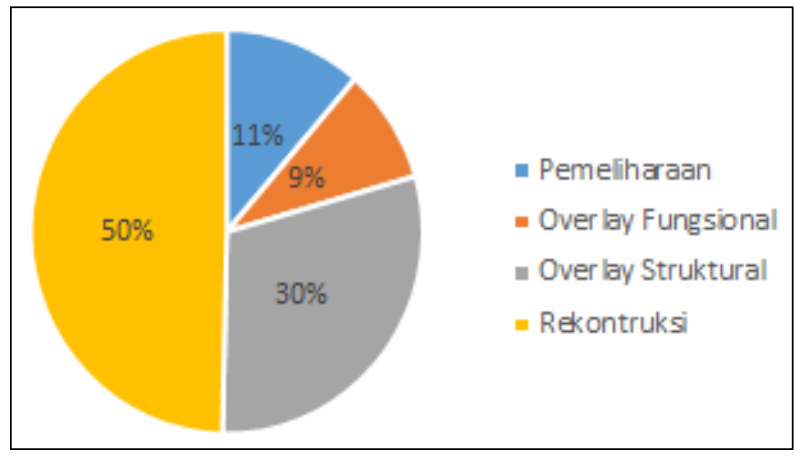

Gambar 5. Persentase Program Penangan Jalan Arah Bulu - Tuban 


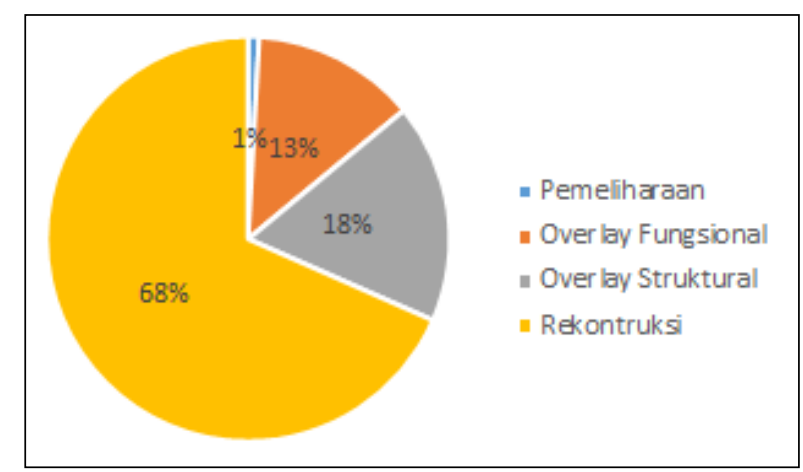

Gambar 6. Persentase Program Penangan Jalan Arah Tuban - Bulu

Segmentasi dilakukan dengan cara mengusahakan setiap segmen mempunyai tingkat keseragaman yang sama (faktor keseragaman < 30\%), hal ini dilakukan agar terhindar dari over desain serta mengefesiensikan dalam perencanaan overlay. Jenis program dan kegiatan penanganan jalan dapat dilihat pada Tabel 5, sedangkan hasil analisis pembagian segmentasi dapat dilihat pada Tabel 6 dan Tabel 7.

Tabel 5. Jenis Program dan Kegiatan Penanganan Jalan

\begin{tabular}{lll}
\hline \multicolumn{1}{c}{ Program Penanganan } & \multicolumn{1}{c}{ Kegiatan Penanganan Jalan } \\
\hline Pemeliharaan Rutin & 1. & Penambalan Lubang (Patching) \\
& 2. & Pembersihan Drainase \\
\hline Pemeliharaan Berkala & 1. & Pelapisan Ulang (Overlay) \\
& 2. & Pemarkaan (Marking) \\
\hline Rekonstruksi Jalan & 3. & Perbaikan dan Pembanguan Fasilitas Drainase \\
& 1. & Pekerjaan galian timbunan \\
& 2. Penyiapan tanah dasar (Subgrade) \\
& 3. Pekerjaan struktur perkerasan (Lapis Fondasi, Lapis \\
& 4. Permukaan) \\
& 5. & Pembangunan fasilitas drainase (Marking) \\
\hline
\end{tabular}

Tabel 6. Rekomendasi Penanganan Segmentasi Arah Bulu-Tuban

\begin{tabular}{|c|c|c|c|c|c|}
\hline \multirow{2}{*}{$\begin{array}{c}\text { No } \\
1\end{array}$} & \multicolumn{3}{|c|}{ Stasioning } & \multirow{2}{*}{$\begin{array}{c}\text { Jarak } \\
(\mathbf{k m})\end{array}$} & \multirow{2}{*}{$\begin{array}{c}\begin{array}{c}\text { Rekomendasi } \\
\text { Penanganan }\end{array} \\
\text { Rekontruksi } \\
\end{array}$} \\
\hline & $107+000$ & - & $110+301$ & & \\
\hline 2 & $110+301$ & - & $131+200$ & 20,9 & Overlay Struktural \\
\hline 3 & $131+200$ & - & $142+400$ & 11,2 & Rekontruksi \\
\hline 4 & $142+400$ & - & $150+401$ & 8 & Pemeliharaan \\
\hline
\end{tabular}

Tabel 7. Rekomendasi Penanganan Segmentasi Arah Tuban-Bulu

\begin{tabular}{|c|c|c|c|c|c|}
\hline \multirow{2}{*}{$\begin{array}{c}\text { No } \\
1 \\
\end{array}$} & \multicolumn{3}{|c|}{ Stasioning } & \multirow{2}{*}{$\begin{array}{c}\begin{array}{c}\text { Jarak } \\
(\mathbf{k m})\end{array} \\
21,4\end{array}$} & \multirow{2}{*}{$\begin{array}{c}\begin{array}{c}\text { Rekomendasi } \\
\text { Penanganan }\end{array} \\
\text { Rekontruksi } \\
\end{array}$} \\
\hline & $106+999$ & - & $128+399$ & & \\
\hline 2 & $128+399$ & - & $132+400$ & 4,401 & Overlay Struktural \\
\hline 3 & $132+400$ & - & $142+378$ & 9,578 & Rekontruksi \\
\hline 4 & $142+378$ & - & $150+400$ & 8,022 & Overlay Fungsional \\
\hline
\end{tabular}




\section{KESIMPULAN}

Berdasarkan hasil kajian penanganan ruas jalan Bulu - Batas Kota Tuban Provinsi Jawa Timur dengan menggunakan data Falling Weight Deflectometer dan survei mata Garuda, didapat beberapa kesimpulan sebagai berikut :

1. Nilai ESAL yang didapat pada ruas jalan Bulu - Batas Kota Tuban Provinsi Jawa Timur adalah 359.632.505 lss/LR/UR dengan asumsi umur rencana selama 5 tahun dan pertumbuhan lalu lintas sebesar 5\% setiap tahunnya.

2. Nilai SCI Ruas Jalan Bulu - Tuban berkisar dari 0,2-1,19, dengan rincian $80 \%$ nilai SCI $<0,7$ dan $20 \%$ nilai SCI > 0,7. Nilai ini memberikan arti bahwa $80 \%$ dari Ruas Jalan Bulu-Tuban telah mengalami kerusakan struktural, sehingga membutuhkan penanganan berupa peningkatan struktur.

3. Nilai SCI Ruas Jalan Tuban-Bulu berkisar dari 0,18-0,98, dengan rincian $86 \%$ nilai SCI $<0,7$ dan $14 \%$ nilai SCI > 0,7. Nilai ini memberikan arti bahwa $86 \%$ dari Ruas Jalan Tuban - Bulu telah mengalami kerusakan structural, sehingga membutuhkan penanganan berupa peningkatan struktur.

\section{DAFTAR PUSTAKA}

[1] AASHTO. (1993). AASHTO Guide for Design of Pavement Structures.

[2] Kementerian Pekerjaan Umum. (2011). Manual Survei Kondisi Jalan. Jakarta: Kementerian Pekerjaan Umum.

[3] Kementerian Pekerjaan Umum. (2013). Manual Desain Perkerasan No. 01/MN/BM/2013. Jakarta: Kementerian Pekerjaan Umum. 